\title{
УДК 556.5.072 \\ ПРИМЕНЕНИЕ МЕТОДОВ КОМПЬЮТЕРНОГО МОДЕЛИРОВАНИЯ ЗОН ЗАТОПЛЕНИЯ ПРИ МАКСИМАЛЬНЫХ РАСЧЕТНЫХ УРОВНЯХ ВОДЫ ДЛЯ РЕШЕНИЯ ПРОЕКТНЫХ ЗАДАЧ ПРИ РЕКУЛЬТИВАЦИИ НАРУШЕННЫХ ЗЕМЕЛЬ, А ТАКЖЕ ПРОЕКТИРОВАНИИ ЗДАНИЙ И СООРУЖЕНИЙ ВБЛИЗИ ВОДНЫХ ОБЪЕКТОВ
}

\author{
Романовский Роман Владимирович, \\ keny146@gmail.com \\ ОАО «Кузбассгипрошахт», \\ Россия, 650000, г. Кемерово, ул. Н. Островского, 34.
}

\begin{abstract}
Актуальность моделирования зон максимального разлива рек (зон затопления) при проведении инженерных изысканий для проектирования и строительства объектов хозяйственной деятельности, разработки проектов рекультивации нарушенных земель в зонах непосредственного влияния водных объектов связана с тем, что в современных условиях, при постоянно растущих требованиях к безопасности и бесперебойности работы проектируемых сооружений, существующие методики оценки опасности затопления не всегда дают удовлетворительный результат, чтобы в полной мере оценить наличие или отсутствие риска для проектируемого сооружения.

Цель работы: анализ отечественного и зарубежного опыта моделирования зон затопления при максимальных уровнях воды рек для практического решения задач инженерного проектирования, оценка достоинств и недостатков основных подходов в практике изысканий, демонстрация возможностей одного из способов моделирования при решении конкретной инженерной задачи. Методы. При подготовке исходных данных для создания цифровой модели рельефа применялся метод анализа пространственных данных при помощи геоинформационных систем, для расчета максимальной зоны затопления - метод численного моделирования зоны затопления р. Иня и расположенной по левому берегу отработанной карьерной выемки в рамках производства работ по подготовке проекта рекультивации нарушенных земель. Численное моделирование выполнялось при помощи моделирующей системы HEC-RAS версии 5.0.5.

Результаты. Произведен обзор существующей мировой и отечественной практики численного моделирования зон затопления рек при решении задач в области инженерного проектирования, приведена собственная модель расчетной зоны затопления на примере участка рекультивации «Моховское поле», показан пример оценки влияния на рекультивируемый объект при реализации наиболее негативного сценария (вероятное затопление карьерной выемки в период прохождения максимального расхода воды 1 \% обеспеченности), описаны достоинства и недостатки применения разных подходов на практике.
\end{abstract}

\section{Ключевые слова:}

Геоинформационные системы, численное моделирование зон затопления рек, 2D моделирование, цифровая модель рельефа, данные дистанционного зондирования земли, моделирующие Cистемы, HEC-RAS.

\section{Введение}

На сегодняшний день математическое моделирование является одной из самых нетривиальных и не установившихся отраслей в гидрологии, в том числе и инженерной. По своей сути моделирование - это способ изучения реально существующих в природе явлений и процессов, имеющих отношение к определенному кругу проблем или задач, а модель - это, в некотором роде, отражение реальности, упрощенное представление о реальном природном процессе, определенным образом организованное и структурированное знание [1].

Однако следует сразу оговориться, что несмотря на то, что практически для любой модели можно подобрать величины параметров, удовлетворяющих решению, в большинстве случаев эти параметры не будут универсальными и не смогут быть прямо экстраполированы на модель при изменении ситуации. В результате различного рода ошибок и погрешностей в измеренных или рассчитанных и принятых для модели данных, а также невозможности в полной мере описать всю сложность и многофакторность природы как некий конечный, строго детерминированный набор пространственно-временных параметров, ни одна модель не может быть рассмотрена как истинное представление природы [2].
Развитие научно-технического прогресса в области проектирования и строительства с каждым годом выводит данную отрасль на более высокий, невиданный доселе технический уровень, заставляя использовать все передовые достижения науки, техники и инженерии.

Одним из важнейших этапов при проектировании является выполнение различного рода инженерных изысканий, которые согласно действующему законодательству являются обязательной частью градостроительной деятельности [3].

Инженерные изыскания в общем случае проводятся с целью получения необходимых и достаточных материалов для принятия обоснованных проектных решений. Таким образом, результаты, полученные в рамках инженерных изысканий, являются фундаментом, на котором будут основаны все последующие проектные решения, места размещения площадок строительства, выбор типа и материала конструкций. Точность и качество определения различных расчетных характеристик при этом будет существенно влиять на сроки безаварийной эксплуатации зданий и сооружений, на экономику и, в конечном итоге, на жизнь людей.

Настоящей статьей рассмотрена такая отрасль инженерных изысканий, как инженерно-гидроме- 
теорологические изыскания, одной из основных задач которых, в частности, является задача определения размера расчетной зоны затопления при максимальных уровнях воды заданной вероятности превышения.

Данная задача может быть решена различными способами, как установленными и официально рекомендуемыми действующей нормативной документацией [4], так и методами численного моделирования гидравлики открытых потоков с использованием различного рода моделирующих систем.

Дан краткий обзор практики компьютерного моделирования зон затопления в России и за рубежом, рассмотрена такая моделирующая система, как HEC-RAS (Hydrologic Engineering Center - River Analysis System) [5, 6], на примере функционала которой автором дано краткое описание процесса моделирования расчетной зоны затопления на участке рекультивации «Моховское поле» на предпроектной стадии изысканий, описан отечественный и зарубежный инженерный опыт в данной сфере, а также проведено сравнение основных типов подходов с выявлением их положительных и отрицательных сторон.

\section{Обзор отечественной и зарубежной практики моделирования расчетных зон затопления}

В настоящее время в области инженерной гидрологии как в России, так и за рубежом становятся все более популярными различные системы для моделирования гидравлики открытых потоков (рек, ру- чьев, каналов и т. д.). При анализе последних статей и исследований в данной области автором было отмечено, что в целом можно выделить два основных принципиальных подхода к решению проблемы моделирования зон затопления: 1) ГИС-ориентированный, или геометрический, подход, отраженный в работах, когда форма кривой свободной поверхности находится путем присвоения заранее рассчитанной отметки уреза для каждого отдельного створа, а затем производится дальнейшая пространственная интерполяция этих отметок выше или ниже по течению с учетом уклона водной поверхности, и 2) собственно гидравлический подход, когда искомые очертания зоны затопления определяются путем решения одно- и двумерных уравнений движения жидкости, нахождения формы кривой свободной поверхности численными методами и наложения полученных отметок на имеющуюся цифровую модель рельефа (ЦМР).

Геолетрический подход. Примеры так называемого ГИС-ориентированного или геометрического подхода нашли свое отражение в статьях [7-11]. Подробно хочется отметить работу [7], где применен классический геометрический подход к решению задачи определения границ расчетной зоны затопления на примере р. Белой средствами программного комплекса ArcGIS путем построения набора плоскостей, которые в некотором приближении описывают поверхность зеркала воды, и нахождения пересечений данных плоскостей с поверхностью ЦМР (рис. 1).

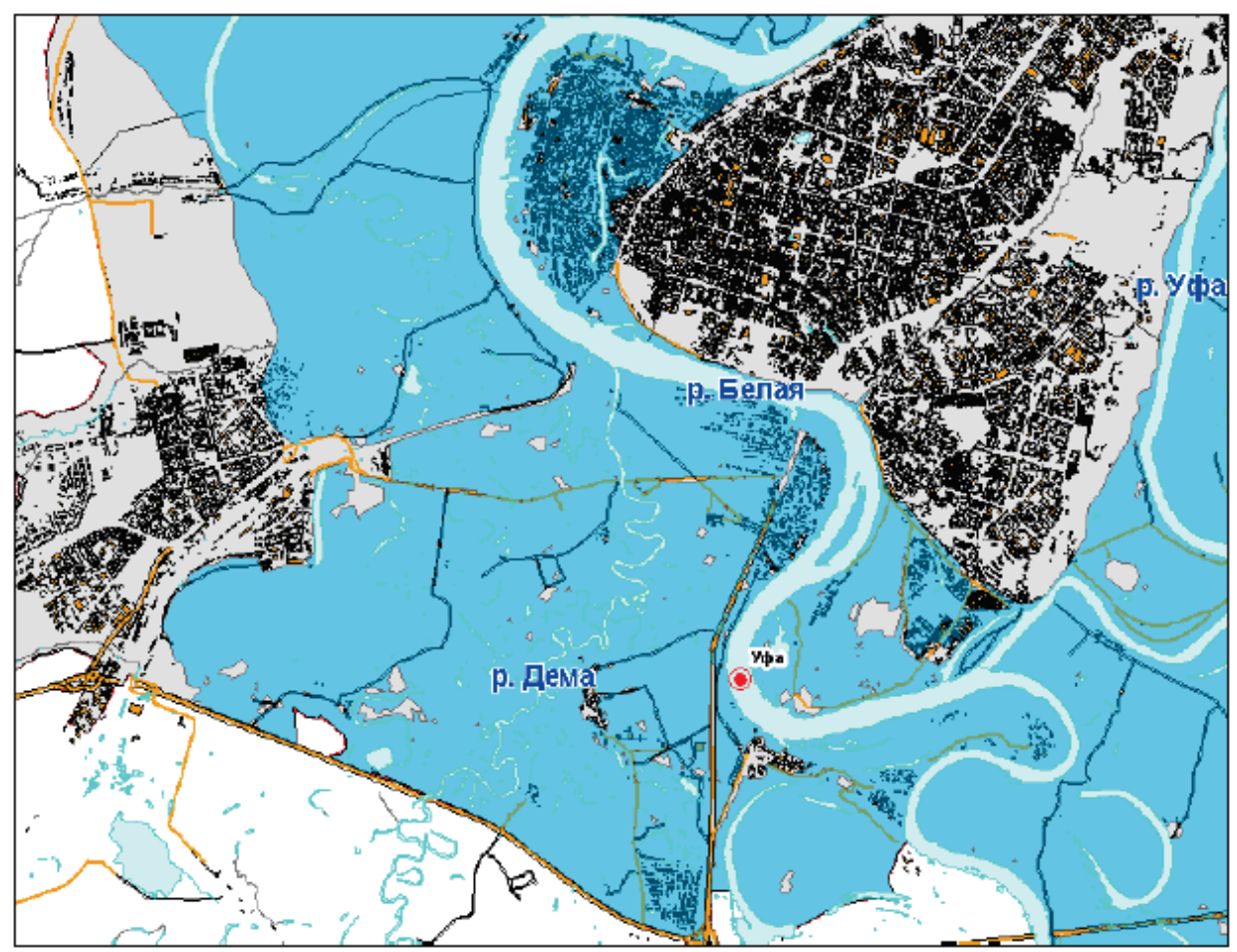

Pис. 1. Пример полученной в работе [7] зоны затопления

Fig. 1. Example of the flood zone obtained in [7] 
Демонстрация полученных результатов осуществляется при этом средствами $3 \mathrm{D}$ визуализации, встроенными в пакет ArcGIS. В работе [8] аналогичным образом, но при помощи системы «Панорама ГИС» на основе топографической съемки создавалась цифровая модель рельефа, в которой на основании постоянного уклона водной поверхности, полученного путем ее нивелировки создавались, и заранее вычисленных расчетных уровней воды создавалась модель зоны затопления в виде наклонной плоскости.

Несколько другой подход к решению проблемы нахождения границ расчетной зоны затопления в рамках геометрического метода удалось реализовать в работе [11], где авторы используют следующий алгоритм. Во-первых, получают ЦМР с использованием SRTM матрицы [12], уточненной результатами единичных промеров по руслу и пойме (так как SRTM-матрица не содержит отметок в самом русле), а также данными с лоцманских карт. Во-вторых, русло реки по всей рассматриваемой длине разбивается поперечными сечениями через определенный интервал, по каждому из таких сечений заранее получена отметка расчетного уровня воды, уровни воды между сечениями передаются по уклону водной поверхности. Далее из полученных абсолютных отметок расчетного уровня воды в пределах каждого участка вычитаются отметки дна русла и поймы, в результате чего получаются пространственно распределенные данные о глубинах воды в предполагаемой зоне затопления, а по нулевым значениям этих глубин проводится результирующий контур границы зоны затопления. Техническая реализация данной методики осуществлялась авторами при помощи САПР $\mathrm{Au}$ tocad Civil 3D, системы баз данных MS Access и различных ГИС пакетов. Оценка валидности методики проводилась путем сравнения полученных расчетных зон затопления с реально наблюдаемыми на космических снимках. Результаты такого сравнения показали достаточно высокую достоверность получаемых границ расчетных зон затопления.

Гидравлический подход нашел свое применение в работах [13-18]. Так, например, в работе [13] было произведено моделирование зоны затопления p. Киндерка - левый приток р. Казанка (г. Казань) на участке длиной около 440 км, находящемся в 8,3 км от устья, с целью оценки опасности затопления и определения безопасных для жилой застройки мест. Моделирующей системой при этом был выбран программный комплекс HEC-RAS (River analysis system) версии 5.0.3, позволяющий peшать задачу гидравлического моделирования кривой свободной поверхности и зоны затопления для установившегося и неустановившегося режима движения воды путем решения одномерных или двумерных уравнений движения жидкости (1D и 2D моделирование), либо их комбинации, в зависимости от задачи. При этом граничные условия могут задаваться совершенно различными спосо- бами, что очень расширяет возможности применения подобных комплексов. В работе [13] задача определения расчетной зоны затопления осуществлялась путем 1D моделирования при установившемся движении воды, а в качестве граничных условий задавались расчетные расходы воды различных вероятностей превышения, для каждой из которых численными методами были получены искомые границы зон затопления. В результате авторами были выделены опасные для застройки, с точки зрения затопления, зоны.

Среди работ иностранных авторов в настоящее время имеет высокую популярность тематика моделирования зон затопления на урбанизированных территориях, как, например, в работе [14], в которой объектом исследования являлась река Lee River в районе Cork City (Ireland). В данном случае характерно, что городская территория располагается в 5 км от устья реки Lee River, которая впадает в Атлантический океан, соответственно, при расчете зоны затопления необходимо учитывать приливы. Таким образом, затопление поймы в пределах города происходит с двух направлений - путем прихода паводочной волны непосредственно по реке и путем прихода приливных и штормовых волн со стороны Атлантики. В период штормов количество жидких атмосферных осадков резко увеличивается и пиковый расход воды возрастает с 40 до $500 \mathrm{~m}^{3} / \mathrm{c}$, а приливные и ветровые волны, доходящие до города, имеют высоту до 0,5 м. Этот комплексный процесс нередко вызывает достаточно сильные наводнения со значительным финансовым ущербом. В статье также показано, что решение данной задачи будет эффективным только при использовании 2D модели, которая реализует численное решение двумерной системы уравнений Навье-Стокса и наиболее адекватно описывает характер движения жидкости при выходе воды на пойму с учетом действия приливных и штормовых волн. Технически решение данной задачи производилось в программном комплексе собственной разработки авторов статьи [14] MSN_Flood (Multi-scale nesting), который позволяет при работе с пространственными данными внедрять детали высокого разрешения в более общую пространственную модель, что по мнению авторов является наиболее эффективным решением для моделирования наводнений на урбанизированных территориях, с точки зрения требований $\mathrm{\kappa}$ компьютерным мощностям.

Основным выводом исследования постулируется, что рассмотренный подход наглядно показывает то, как численные модели помогают лучше понять динамику распространения наводнения, обладают большим потенциалом для пространственного и временного анализа наводнений, а также могут существенно облегчить работу при планировании противопаводковых мероприятий и ликвидации их последствий.

В работе китайских коллег [15] показано решение задачи гидравлического моделирования зоны 
затопления при гипотетическом прорыве плотины водохранилища Qingshan Reservoir. Данной работой показано, что при моделировании затоплений, связанных с прорывом плотин и дамб, и движении большого потока воды вне русла рек (как это обычно бывает при подобных авариях) наиболее обоснованным, по мнению авторов работы, является применение 2D моделей, как наиболее адекватно описывающих процесс затопления при неустановившемся режиме движения жидкости, а также дающих возможность получить пространственное распределение глубин и скоростей потока.

В статье [16] показан пример совмещения моделирования стока и получения модели гидрографа и, собственно, гидравлического моделирования заданного участка реки в один комплекс. При этом гидравлическая модель была реализована в моделирующей системе HEC-RAS. C точки зрения разработки гидравлической модели, в данной работе была изучена работа так называемой саморегулирующейся дамбы (self-regulated flood dam, SRFD), которая призвана регулировать сток в период паводка, а излишки воды сбрасывать в автоматическом режиме в нижний бьеф, и ее влияние на паводковую ситуацию. Результатом данной работы является вывод о том, что разработка подобных комплексных стоково-гидравлических моделей является достаточно эффективным инструментом при решении задач по выбору места размещения различных защитных или выполняющих регулирующую функцию гидротехнических сооружений, а также для целей водно-ресурсного планирования.

В работе [17] довольно подробно освещена проблематика, теоретическая часть и методика моделирования зоны затопления реки Mamore river, протекающей на равнине Llanos de Moxos в Боливии. Гидравлическая модель реализована на базе моделирующей системы HEC-RAS, версии 5, а в качестве численной модели была принята 2D модель. Основной предпосылкой для выбора 2D модели в данной работе является обоснованный ссылками на соответствующие работы и исследования вывод о том, что данная модель более адекватно описывает процесс затопления при выходе воды на пойму. Также авторами отмечено, что достаточно серьезный потенциал имеют гибридные 1D-2D модели, описывающие как движение воды в русле, так и движение воды после ее выхода на пойму, причем для каждого из этих режимов используется свой метод расчета. Результатами данной работы был детально показан процесс затопления поймы, получены границы зоны затопления, временные и пространственные ее характеристики, выполнена оценка риска для близлежащих городов Тринидад и Сан-Хавьер, сделан акцент на высокой эффективности подобного подхода, а также на высоком потенциале моделирующей системы HEC$\mathrm{RAS}$, как наиболее доступной и при этом обладающей достаточно серьезным функционалом для решения подобных задач.
В контексте решения научных задач широко применяется практика использования продвинутых в функциональном отношении коммерческих моделирующих систем, таких как SMS (Surfacewater modelling system). Исторически, на заре своего возникновения в 1980-х гг., комплекс SMS разрабатывался Корпусом военных инженеров армии США и состоял из большого числа модулей, необходимых для решения различного рода задач, связанных с гидравлическим моделированием рек, устьевых участков рек, моделированием волн и т. д., в том числе и модуля по моделированию речной гидравлики HEC-RAS. Впоследствии команда разработчиков SMS перешла в другую компанию, а системы SMS и HEC-RAS стали развиваться параллельно, постепенно теряя сходства и приобретая свои отличительные черты. На сегодняшний день система SMS довольно широко применяется для моделирования речной (морской) гидравлики при решении научных и практических задач, имея при этом свои очевидные достоинства и недостатки.

Так, в работе [18] путем численного моделирования изучалась схема течений, которая могла бы существовать при сбросе ледниково-подпрудного озера в Курайской котловине. Хотя основной линией данного исследования было изучение, на базе двумерной компьютерной модели, распределения течений, в качестве побочного результата была получена граница зоны затопления, вызванная гигантским водным потоком в результате опорожнения Чуйского и Курайского озер, имевшего место быть в рамках теории дилювиальных потоков. Цифровая модель рельефа в данной работе создавалась на базе SRTM матрицы, на основе современного рельефа местности. Полученные в рамках данного исследования результаты авторы характеризуют как предварительные, однако сопоставление этих результатов с ориентацией дюн на дне Курайской котловины, а также с результатами ранее проведенных палеогидрологических реконструкций показало хорошую их сходимость.

Для обоих подходов объединяющим фактором является то, что основой для качественного определения границ расчетной зоны затопления является качество исходной ЦМР. Нередко для решения задач определения границ расчетных зон затопления на достаточно протяженных участках рек используются данные дистанционного зондирования земли (ДЗ3), такие как SRTM, LIDAR, ASTER Global DEM и др. Матрицы высотных отметок, полученные из открытых источников, должны уточняться по данным локальных промеров, топографических съемок либо крупномасштабных карт в русловых и пойменных областях исследуемых водотоков.

В работе [19], в частности, описана методика улучшения высотной матрицы TanDEM-X при помощи SAR (Synthetic-aperture radar) технологии, которая позволяет получать данные о форме земной поверхности при помощи методов радиолокации. 
В целом качество существующих на сегодняшний день цифровых моделей рельефа описано во многих статьях. Так, в статье [20] произведена оценка качества и сравнение таких глобальных ЦMР, как Aster GDEM и SRTM DEM, которая показала, что обе ЦМР имеют достаточно широкий разброс в точности данных в зависимости от степени пересеченности рельефа, наличия или отсутствия на конкретном участке древесной растительности и других факторов. В общем случае для обеих матриц пространственное разрешение колеблется от 25 до $30 \mathrm{~m}$, а разрешение по высотным отметкам колеблется в среднем от 3 до $10 \mathrm{~m}$.

Таким образом, при использовании любых глобальных ЦМР для моделирования расчетных зон затопления рек, в зависимости от целей и задач, русловые и пойменные участки рекомендуется уточнять дополнительными промерами и съемками. На практике, при решении изыскательских и инженерных задач, где требуется достаточно точная оценка угрозы затопления проектируемого объекта, рельеф дна и поймы должен быть обязательно уточнен путем русловой съемки и детальных топографических работ. Использование для подобных задач только лишь глобальных SRTM или Lidar матриц некорректно, так как погрешность определения уровня воды в таком случае может достигать трех и более метров, что является абсолютно неприемлемым. Для решения многих научных задач и некоторых практических, когда моделируется прохождение особенно больших расходов воды (например, при прорыве плотин водохранилищ), данная погрешность не будет иметь значения, так как качество отображения рельефа русла и поймы практически не будет влиять на отметки уровня воды при прохождении катастрофического расхода воды, а роль русла будет играть долина реки либо иные орографические элементы.

\section{Моделирование расчетной зоны затопления} на примере участка рекультивации нарушенных земель в зоне непосредственного влияния р. Иня

В настоящей статье приведен собственный пример моделирования расчетной зоны затопления $\mathrm{p}$. Иня, выполненный автором в рамках гидрологического обеспечения работ по рекультивации нарушенных земель участка «Моховское поле» в Кемеровской области.

Краткие сведения о районе работ. Моховский угольный разрез был образован в 2009 г. путем слияния трех филиалов (разрезов) компании - Моховского, Сартакинского и Караканского. Моховское поле филиала расположено в юго-западной части Ленинск-Кузнецкого района в Ленинском и Салтымаковском геолого-промышленных районах Кузнецкого бассейна и находится в центральной части Егозово-Красноярского и Борисовского месторождений. Поле ликвидируемого участка № 8 (Южное замыкание Ленинской синклинали) располагается в юго-восточной части Ленинского геолого-экономического района Кузбасса. В непосред- ственной близости от участка расположена железнодорожная станция «Мереть». Ближайшими населенными пунктами являются: г. Полысаево, п. Красногорский, п. ст. Мереть, п.г.т. Грамотеино. В 2 км восточнее участка проходит шоссейная дорога I категории, соединяющая города ЛенинскКузнецкий и Белово. Участок № 8 приурочен к долине реки Иня. Наивысшая абсолютная отметка рельефа в настоящее время составляет 220,4 м БС, наиболее низкая 92,0 м БС (в карьерной выемке).

Краткая математическая основа работы двумерной модели (2D) неустановившегося движения

Модель строилась с использованием моделирующей системы HEC-RAS версии 5.0.5 по схеме 2D моделирования, подробная физико-математическая основа работы которой очень детально описана в руководствах к программе HEC-RAS и научных работах [21-26]. Выбор типа моделирующей системы производился автором по принципу соотношения функциональности и доступности программного обеспечения для широкого круга пользователей. Программное обеспечение HEC-RAS предоставляется на условии его свободного распространения, но в то же время данная моделирующая система является полнофункциональной и пригодной для решения практических и научных задач по моделированию речной гидравлики.

Поставленная задача решалась путем применения так называемой двумерной модели (2D модель), которая реализует в себе решение двумерного уравнения Сен-Венана (при опциональном учете турбулентного момента и силы Кориолиса) либо двумерного уравнения Диффузной Волны (Diffusion Wave equation). Уравнения «мелкой воды» в той форме, в которой они реализуются в рассматриваемой моделирующей системе HEC-RAS, coстоят в общем случае из уравнения неразрывности и уравнений динамического равновесия, которые кратко затронем ниже.

Уравнение неразрывности в дифференциальной форме имеет вид (1):

$$
\frac{\partial H}{\partial t}+\frac{\partial(h u)}{\partial x}+\frac{\partial(h v)}{\partial y}+q=0,
$$

где $t$ - время; $u$ и $v$ - горизонтальные и вертикальные компоненты скорости; $q$ - переменная, отражающая дополнительный приток/отток жидкости на моделируемом участке.

Уравнение (1), но в интегральной форме, применяется в контексте метода рельефной «суб-сетки» (sub-grid bathymetry approach), используемого в системе HEC-RAS [25]. Идея данного подхода представляет собой определенный компромисс, при котором вместо непосредственного использования в расчетах «тяжелых» данных о рельефе высокого разрешения используют облегченный набор пространственных данных (суб-сетка), но с предварительно вычисленной на основе данных высокого разрешения дополнительной атрибутивной информацией, такой как гидравлический радиус, объем 
и смоченный периметр. Детали высокого разрешения при этом теряются, но в системе остается вся необходимая информация для того, чтобы численными методами найти решение задачи через уравнение неразрывности.

Уравнения динамического равновесия. Закон неразрывности в общем случае гласит, что если горизонтальные масштабы акватории много меньше вертикальных, то вертикальные составляющие скорости малы и ими можно пренебречь. Уравнение Навье-Стокса для вертикальной составляющей скорости может быть использовано, чтобы обосновать, что давление стремится к гидростатическому. В открытом речном потоке воздействие атмосферы в виде бароклинических градиентов давления (при переменной плотности среды) и силы касательного напряжения ветра являются несущественными и ими можно пренебречь. Вертикальная скорость и ее производные составляющие могут быть, таким образом, исключены из уравнений (в обоих случаях для уравнения неразрывности и динамического равновесия). Тогда уравнения «мелкой воды» принимают вид (2), (3):

$$
\begin{gathered}
\frac{\partial u}{\partial t}+u \frac{\partial u}{\partial x}+v \frac{\partial u}{\partial y}= \\
=-g \frac{\partial H}{\partial x}+v_{t}\left(\frac{\partial^{2} u}{\partial x^{2}}+\frac{\partial^{2} u}{\partial y^{2}}\right)-c_{f} u+f v,
\end{gathered}
$$

$$
\begin{gathered}
\frac{\partial v}{\partial t}+u \frac{\partial v}{\partial x}+v \frac{\partial v}{\partial y}= \\
=-g \frac{\partial H}{\partial y}+v_{t}\left(\frac{\partial^{2} v}{\partial x^{2}}+\frac{\partial^{2} v}{\partial y^{2}}\right)-c_{f} v+f u,
\end{gathered}
$$

где $u$ и $v$ - скорости в Декартовой системе координат; $g$ - ускорение свободного падения; $v_{t}-$ коэффициент горизонтальной турбулентной вязкости жидкости; $c_{f}-$ коэффициент донного трения; $R-$ гидравлический радиус; $f$ - параметр силы Кориолиса.

Для того чтобы эффективно использовать численные методы решения, территория разбивается на множество не перекрывающих друг друга полигонов, образующих сетку. У алгоритма решения нет строгих внутренних ограничений в отношении количества сторон для полигональных ячеек сетки, однако разработчиками системы HEC-RAS для улучшения производительности и эффективного использования ресурсов памяти ЭВМ это количество намеренно было ограничено до восьми. В силу того, что в расчетах используется второй порядок производных, а также из-за дифференциальной природы взаимосвязей между переменными, дополнительно к регулярной сетке ячеек в системе используется дублирующая сетка, которая служит для того, чтобы численно решать дифференциальные уравнения. Дублирующая сетка также охва-

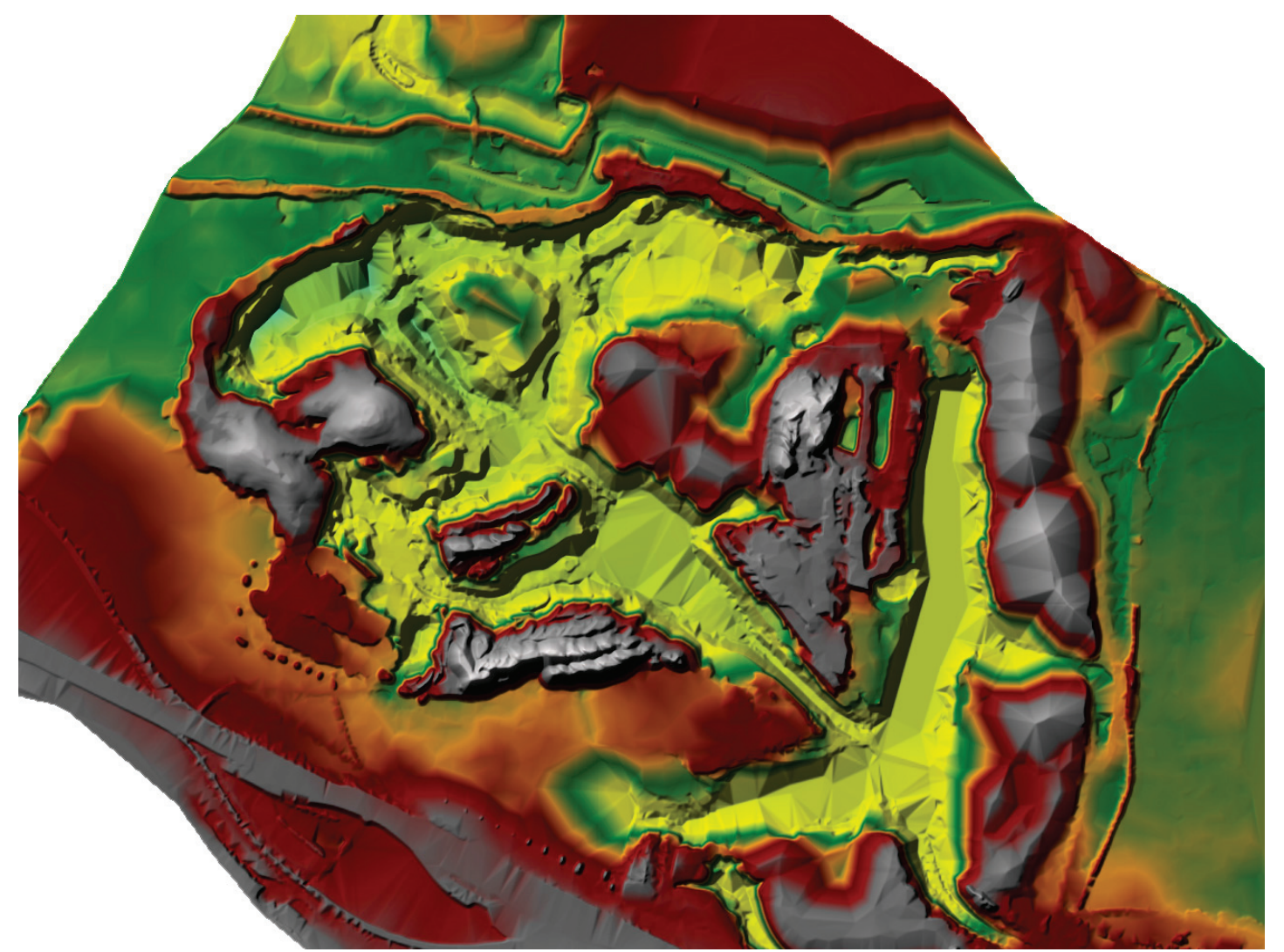

Рис. 2. Цифровая модель рельефа участка реки и прилегающей отработанной карьерной выемки участка № 8 «Моховского поля»

Fig. 2. Digital elevation model (DEM) of the simulated section of the river and adjacent abandoned quarry excavation of section No. 8 of "Mokhouskoe pole» 


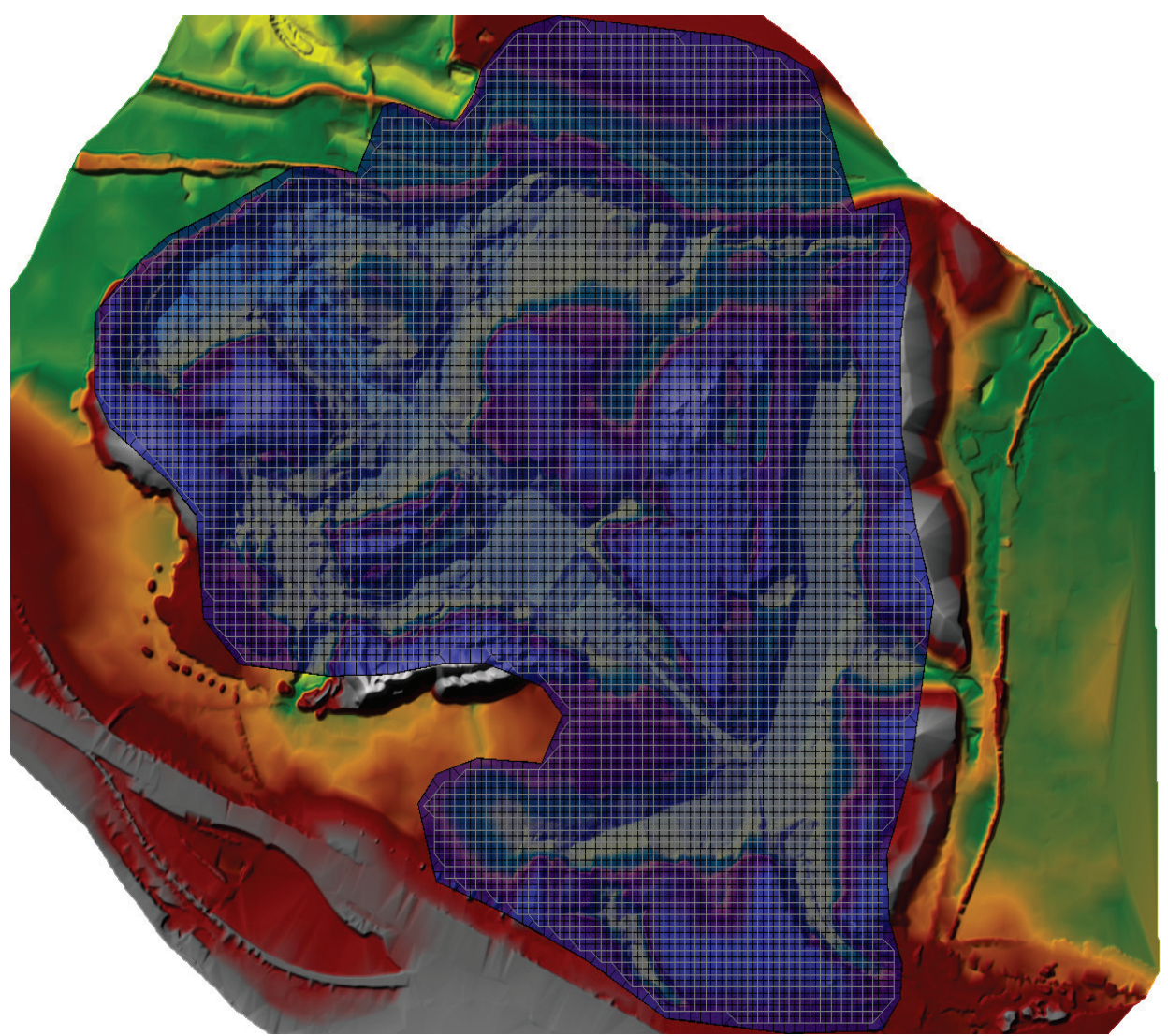

Рис. 3. Положение расчетной $2 D$ сетки ячеек на рассматриваемой ЦМР (показана в виде закрашенной фиолетовым иветом области, разделенной на ячейки)

Fig. 3. Position of the calculated 2D grid of cells on the considered DEM (shown as a violet-colored area divided into cells)

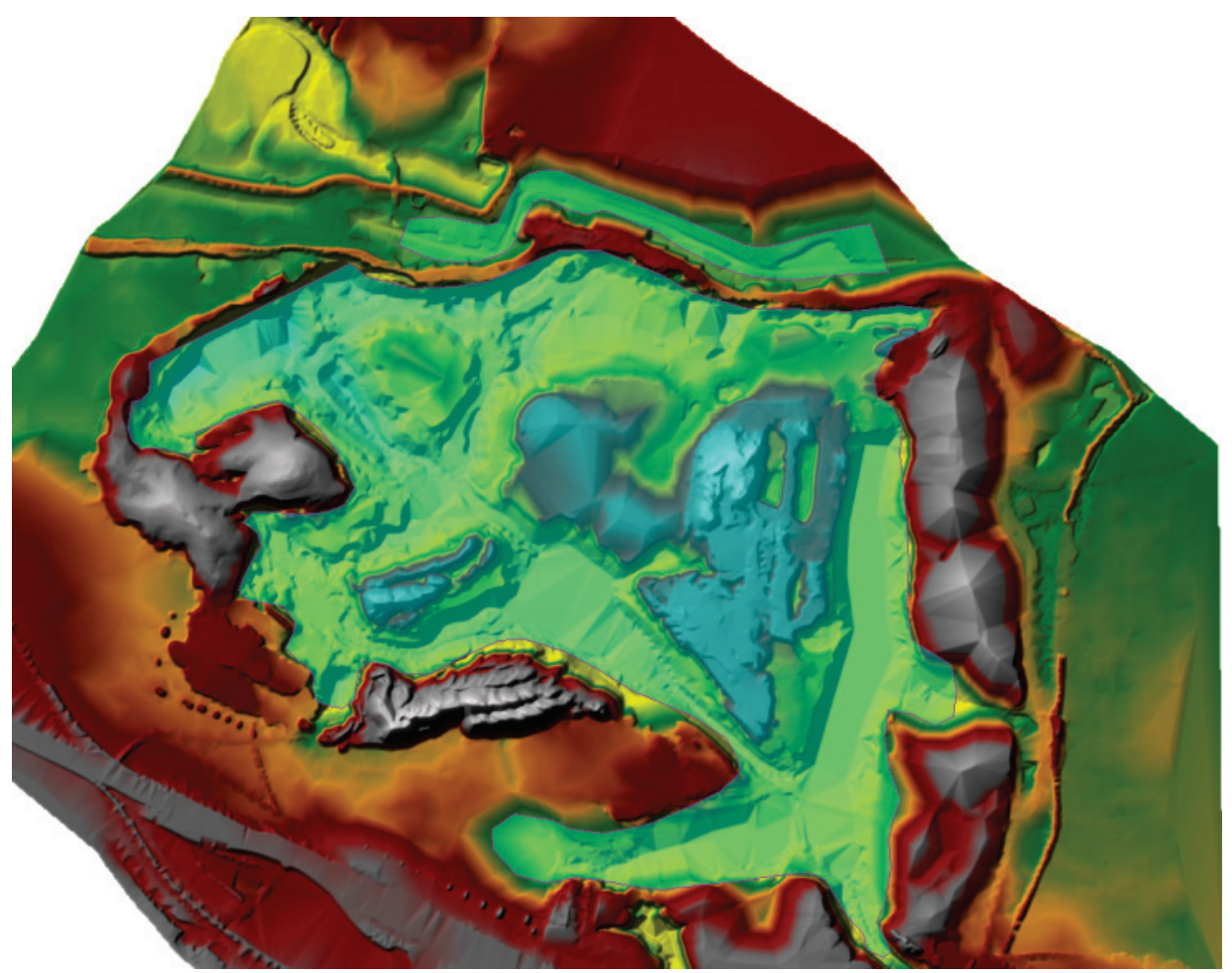

Puс.4. Зоны коэффициентов шероховатости для различных участков (Manning’s regions), для русловой части потока и карьерной выемки

Fig. 4. Zones of roughness coefficients for various sites (Manning's regions), for the channel part of the stream and quarry excavation 
тывает всю рассматриваемую территорию и служит для определения соотношения между узлами дублирующей сетки и ячейками ординарной сетки, а равно и между ячейками дублирующей сетки и узлами регулярной сетки. Схема гибридной дискретизации, реализованная в HEC-RAS, соединяет в себе использование методов конечных разностей и конечных объемов.

Методика создания и настройки модели. B первую очередь, при помощи ГИС пакета SAGA GIS и CAПP Civil 3D была подготовлена цифровая модель рельефа исследуемого участка реки на базе материалов аэрофотосъемки и промеров в русле реки и в затопленных горных выработках (рис. 2).

Полученная ЦМР была импортирована в моделирующую систему HEC-RAS версии 5.0.5 с помощью встроенной в систему программы по работе с ГИС данными RAS-Mapper, где с помощью инструментария Geometric data на цифровую модель рельефа была нанесена расчетная сетка 2D ячеек (рис. 3), заданы параметры коэффициентов шероховатости русловой части потока и участка карьерной выемки (рис. 4).

Причем, для задания коэффициентов шероховатости, отдельно для участка русла и карьерной выемки, использовалась функция Manning's region, которая реализует введение параметров шероховатости в границах заданной границы (региона). Подробная информация по выбору коэффициентов шероховатости русел, пойм и других поверхностей представлена в руководстве [27]. В рассматриваемой модели для русловой части водотока был задан коэффициент шероховатости, равный 0,025 (естественные земляные русла), для карьерной выработки - 0,065 (что соответствует скалистым и порожистым руслам с большими уклонами), для всех остальных отдельно не выделенных областей - 0,06 (эквивалентен сильно заросшим поймам рек с зарослями кустарниковой растительности).

Входные данные для модели (начальные условия). В связи с тем, что в 11 км выше рассматриваемого участка расположено Беловское водохранилище, - сток р. Иня зарегулирован. По информации Кузбасского филиала ОАО «Кузбассэнерго» «Беловская ГРЭС»- величина расчетного расхода воды 1 \% обеспеченности при сбросе из водохранилища составляет $315 \mathrm{~m}^{3} / \mathrm{c}$.

На участке р. Иня от нижнего бьефа плотины до исследуемого участка имеется лишь один относительно крупный приток - р. Бачат, которая впадает слева на 538 км от устья и имеет расчетную площадь водосбора, равную $1720 \mathrm{kм}^{2}$ [28].

При разработке модели автором был предложен сценарий, при котором пик половодья на р. Иня, формирующийся с водосборной площади ниже Беловского водохранилища, совпадает с его максимальными попусками $1 \%$ вероятности превышения. Таким образом, расчетный расход 1 \% обеспеченности $\mathrm{p}$. Иня на рассматриваемом участке будет складываться из расчетного расхода воды 1 \% обеспеченности на сбросе Беловского водохранилища и расхода воды 1 \% обеспеченности р. Бачат в ее устьевой части. Так как для р. Иня в годовом ходе водного режима наибольшие величины стока формируются в период весеннего половодья, расчет будет производиться для фазы весеннего половодья.

Расчетные максимальные расходы воды весеннего половодья определенны согласно п. 7.28 СП 33-101-2003. Результаты расчета максимальных расходов весеннего половодья приведен в табл. 1 .

Таблица 1. Результаты расчета максимальных расходов воды весеннего половодья, $\mathrm{m}^{3} / \mathrm{c}$

Table 1. Results of calculating the maximum water flow in spring high water, $\mathrm{m}^{3} / \mathrm{s}$

\begin{tabular}{|c|c|c|c|c|c|}
\hline \multirow{2}{*}{$\begin{array}{c}\text { Водотоки } \\
\text { Streams }\end{array}$} & \multicolumn{5}{|c|}{$\begin{array}{c}\text { Обеспеченность расхода, } \% \\
\text { Расход воды, } \mathrm{m}^{3} / \mathrm{c} \\
\text { Occurrence of water flow, \% } \\
\text { Water flow, } \mathrm{m}^{3} / \mathrm{s}\end{array}$} \\
\hline & 1 & 2 & 3 & 5 & 10 \\
\hline $\begin{array}{c}\text { p. Бачат } \\
\text { the Bachat river }\end{array}$ & 267 & 245 & 228 & 206 & 178 \\
\hline
\end{tabular}

Таким образом, суммарный расход воды р. Иня $1 \%$ обеспеченности при предложенном неблагоприятном сценарии на рассматриваемом участке, с учетом попусков с Беловского водохранилища и максимального стока р. Бачат, составит $582 \mathrm{~m}^{3} / \mathrm{c}$.

В качестве гидрографа, задаваемого в модели, был принят гидрограф, смоделированный по методике, описанной в СП 33-101-2003. В качестве гидрографа-модели при этом использовался реальный гидрографр р. Иня по данным водомерного поста г. Ленинск-Кузнецкий за наиболее многоводный 1966 г. [29]. Выборка гидрографа-модели осуществлялась автором из имеющихся в его распоряжении данных за период наблюдений с 1962 по 2005 гг. Выбор гидрографа-модели обусловлен тем, что гидрологический пост в г. Ленинск-Кузнецкий расположен ниже Беловского водохранилища и наилучшим образом описывает режим стока на данном участке реки. Смоделированный и заданный в качестве одного из граничных условий гидрограф весеннего половодья показан на рис. 5 .

Калибровка модели и граничные условия. В качестве граничных условий по руслу реки Иня на входном створе был задан расчетный гидрограф стока, а на замыкающем - уклон водной поверхности, на данном участке составляющий 0,0002 $(0,2$ $\%$ ). Также в качестве граничного условия была задана существующая защитная дамба, построенная с целью защиты горной выработки от затопления водами р. Иня (рис. 6).

Калибровка модели производилась по измеренному расходу и уровню воды р. Иня, сравнению измеренных данных с полученными по модели в одном и том же створе и подбору таких коэффициентов шероховатости, при которых получаемая в результате моделирования отметка уровня воды будет как можно ближе к измеренной при данном расходе воды. Вследствие такой калибровки автором получены результаты, приведенные в табл. 2. 


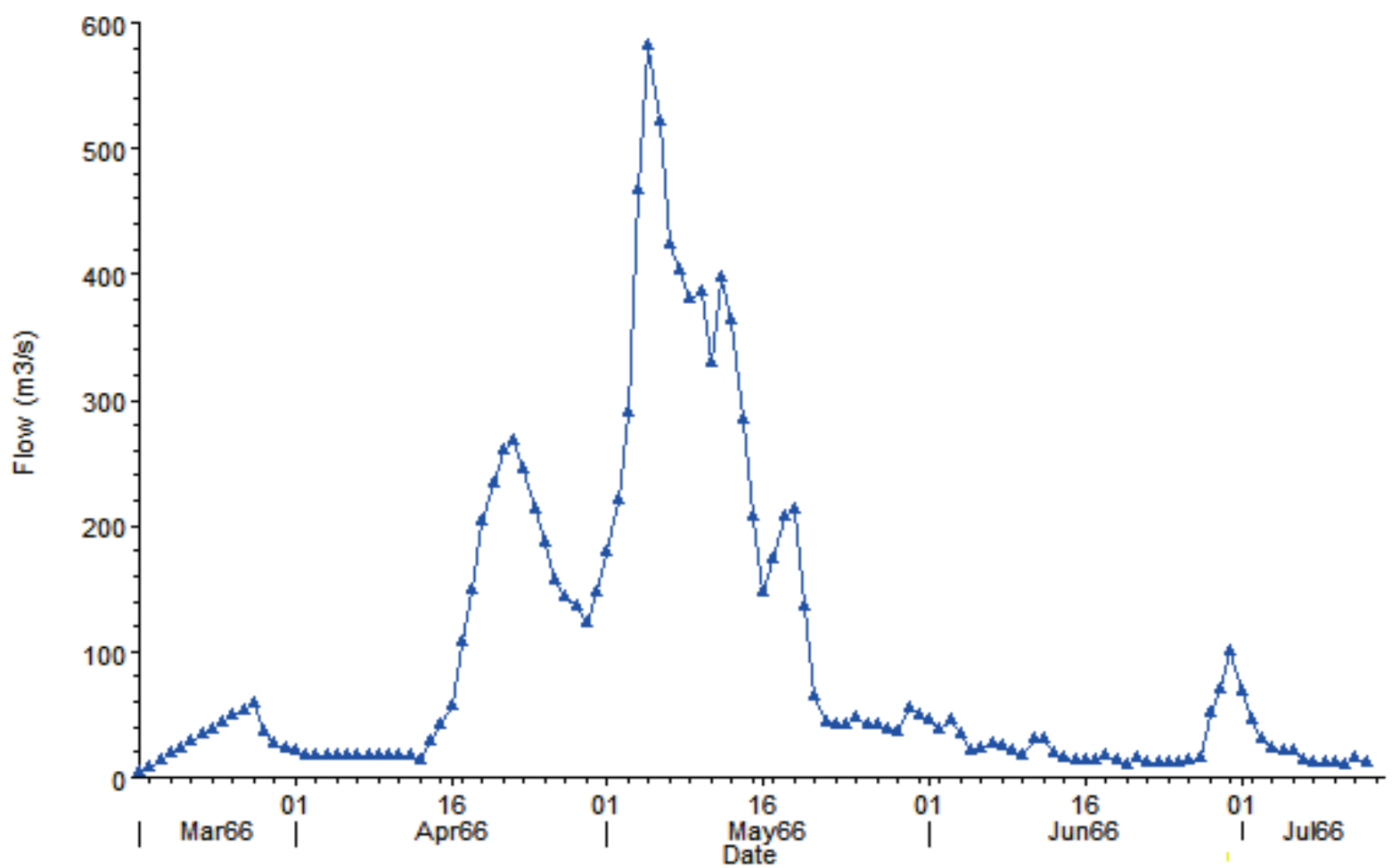

Pис. 5. Используемый для гидравлической модели смоделированный гидрограф половодья р. Иня на рассматриваемом участке

Fig. 5. Modeled hydrograph of the Inya river flood in the area under consideration used for the hydraulic model

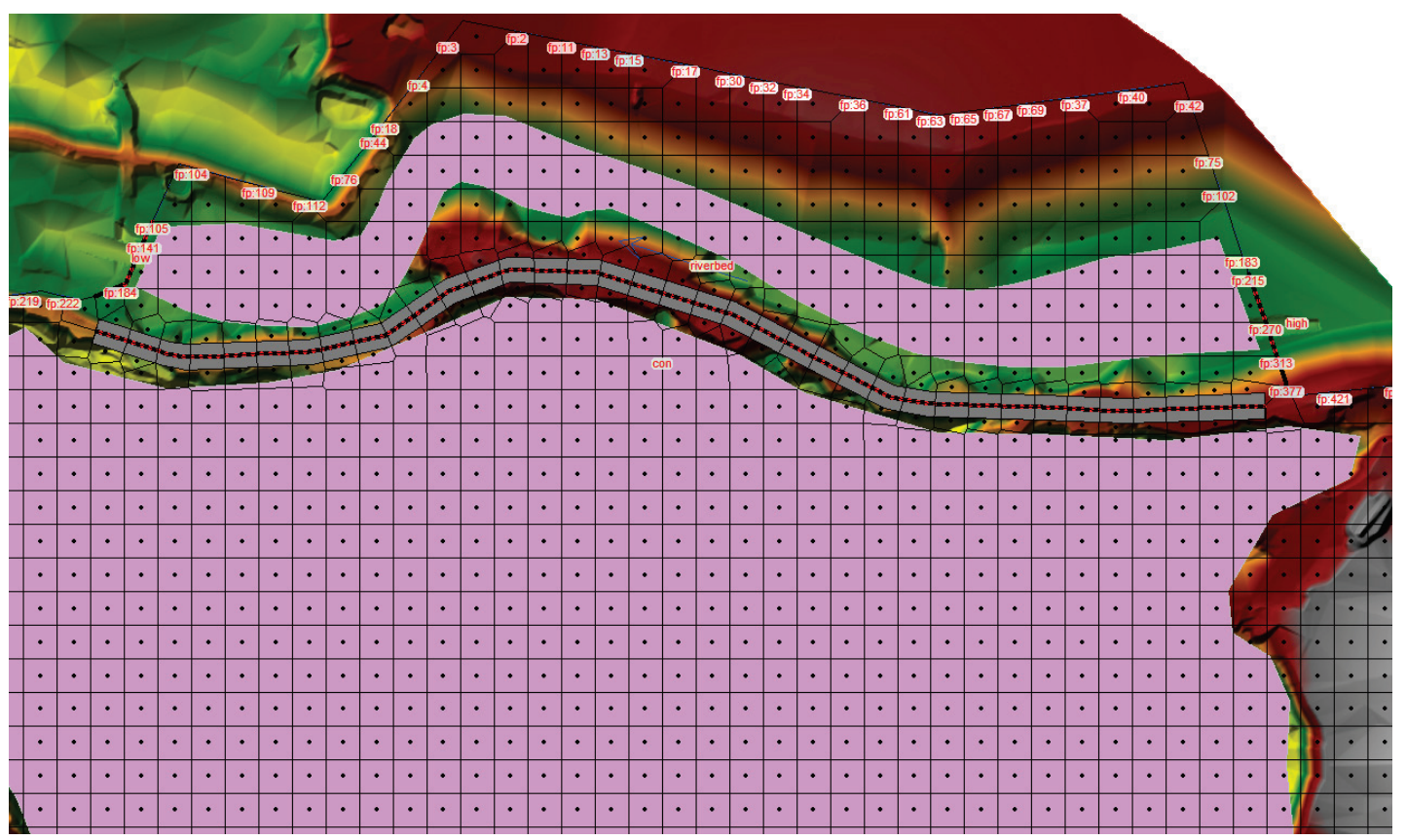

Рис. 6. Заданная в качестве граничного условия существующая защитная дамба (показана серой линией)

Fig. 6. Existing protective dam (shown by the gray line) defined as a boundary condition

Как следует из результатов сравнения, расхождение смоделированных величин с реально наблюденными уровнями составило 0,23 м. Стоит принять во внимание, что измерение расхода воды производилось 16.05.2018 г., на спаде половодья, поэтому на качество смоделированной величины уровня сильно влияет качество исходной ЦМР. Автором было сделано предположение о том, что при существенно больших расходах воды, таких как расчетный $1 \%$ расход, влияние мелких артефактов и неточностей исходной ЦМР будет играть все меньшую роль по мере нарастания расхода воды и энергии потока. 
Таблица 2. Результаты сравнения слоделированных расходов и уровней воды с реально наблюденныли

Table 2. Results of comparison of the modeled water flow and water levels with those actually observed

\begin{tabular}{|c|c|c|c|}
\hline $\begin{array}{l}\text { Расход воды } \\
\text { наблюден- } \\
\text { ный, }{ }^{3} / \mathrm{c} \\
\text { Observed wa- } \\
\text { ter flow, } \mathrm{m}^{3} / \mathrm{s}\end{array}$ & $\begin{array}{c}\text { Отметка } \\
\text { наблюденного } \\
\text { уровня воды, м БС } \\
\text { Mark of the obser- } \\
\text { ved water level, m } \\
\text { BS }\end{array}$ & $\begin{array}{l}\text { Расход воды } \\
\text { смоделиро- } \\
\text { ванный, } \mathbf{m}^{3} / \mathrm{c} \\
\text { Modeled wa- } \\
\text { ter flow, } \mathrm{m}^{3} / \mathrm{s}\end{array}$ & $\begin{array}{c}\text { Отметка смодели- } \\
\text { рованного уровня } \\
\text { воды, м БС } \\
\text { Mark of the mode- } \\
\text { led water level, m } \\
\text { BS }\end{array}$ \\
\hline 10,94 & 176,48 & 10,94 & 176,61 \\
\hline
\end{tabular}

В качестве результата расчетов были получены следующие данные:

- гидрограф стока в замыкающем створе с учетом его трансформации и потерь части стока при переливе через защитную дамбу в карьерную выемку (определяющихся как разница между расходом воды, ушедшим в горную выработку, и начальными условиями) (рис. 7);

- максимальная зона затопления р. Иня и прилегающей к ней отработанной карьерной выемки (рис. 8);

- расчетное поле глубин потока и карьерной выемки (рис. 9);

- распределение направлений течения и расчетное поле значений скоростей потока с локализацией зон перелива воды через защитную дамбу (рис. 10).
При повышении расходов и уровней воды в реке Иня на рассматриваемом участке и выходе ее из берегов ширина потока увеличивается до тех пор, пока с правой стороны река не упрется в коренной берег, а слева в дамбу, защищающую отработанную карьерную выработку от попадания речных вод. Далее поток движется в условиях его стеснения, при этом возрастают скорости и уровни воды. Так, например, в работе [30] была произведена оценка эффективности противопаводковой дамбы на реке Томь в районе г. Междуреченска. Моделирование гидрологических процессов производилось с применением программного комплекса «River» (авт. В.В. Беликов и др.) и ГИС-технологий. Результатом оценки явился вывод о том, что повышение уровня воды за счет стеснения живого сечения потока телом дамбы при ее наращивании может достигать 0,5 м.

В рассматриваемой модели расчетной зоны затопления р. Иня на участке рекультивации выявлены две зоны, в которых возможен перелив воды в емкость отработанной карьерной выемки при рассмотренном сценарии. Данные зоны выявлены посредством локализации областей в пределах дамбы, где резко возрастают скорости потока и вектора направлений течения меняют свое направление на ортогональное к дамбе.

Превышение расчетных отметок уровня воды над гребнем дамбы при переливе укладывается в

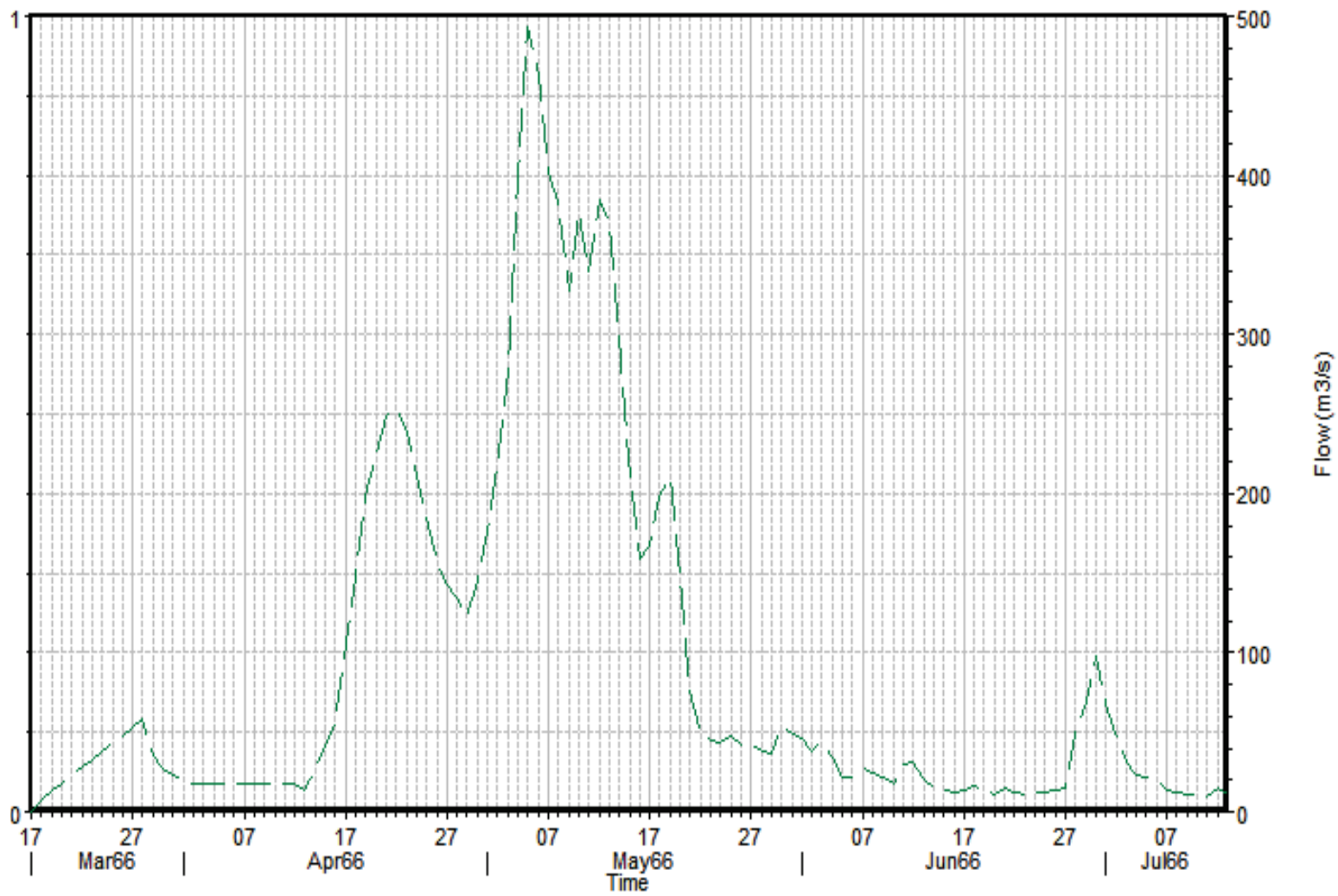

Pис. 7. Гидрограф стока в залыкающем створе с учетол его трансформации и потерь части стока при переливе через защитную дамбу в отработанную карьерную выемку

Fig. 7. Flow hydrograph at the outflow cross-section taking into account flow transformation and loss during overflow through the protective dam into the abandoned quarry 


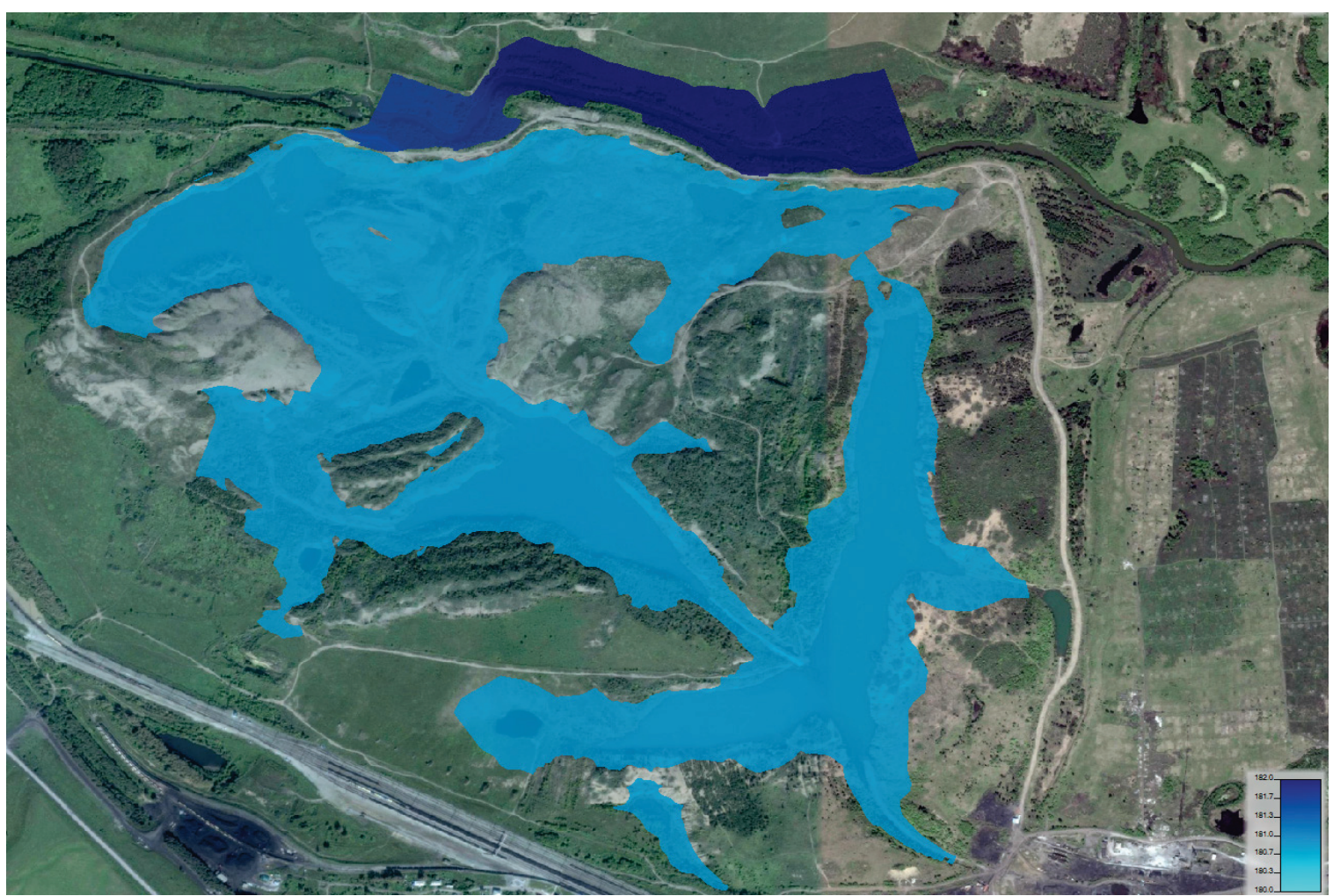

Рис. 8. Максимальная зона затопления р. Иня (синий цвет) и прилегающей к ней отработанной карьерной выемки (голубой цвет)

Fig. 8. Maximum flood zone of the Inya river (blue color) and the adjacent quarry excavation (light blue color)

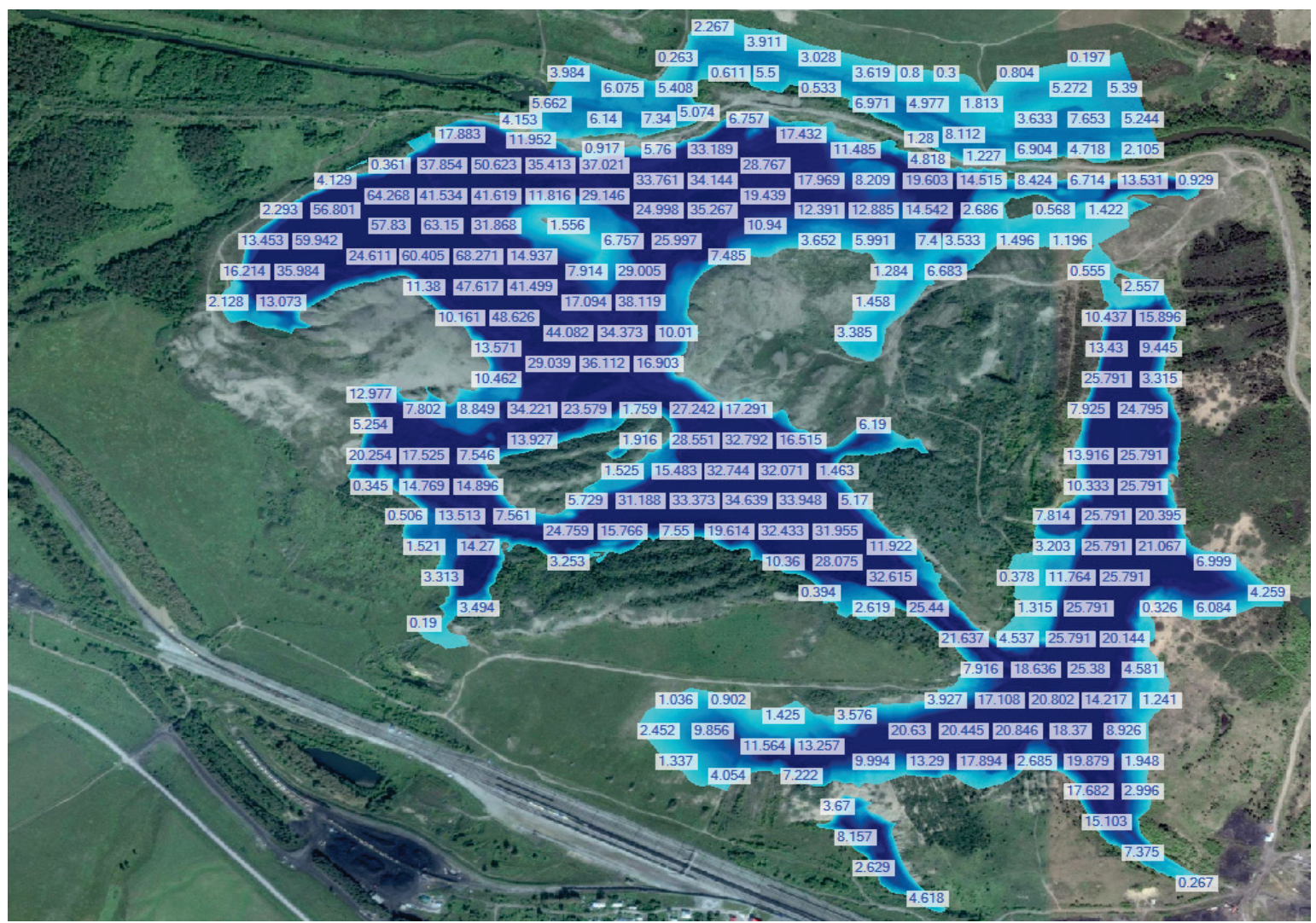

Рис. 9. Расчетное поле глубин при максимальном уровне воды р. Иня и в карьерной выемке

Fig. 9. Calculated depth field at the maximum water level of the Inya river and in the quarry excavation area 


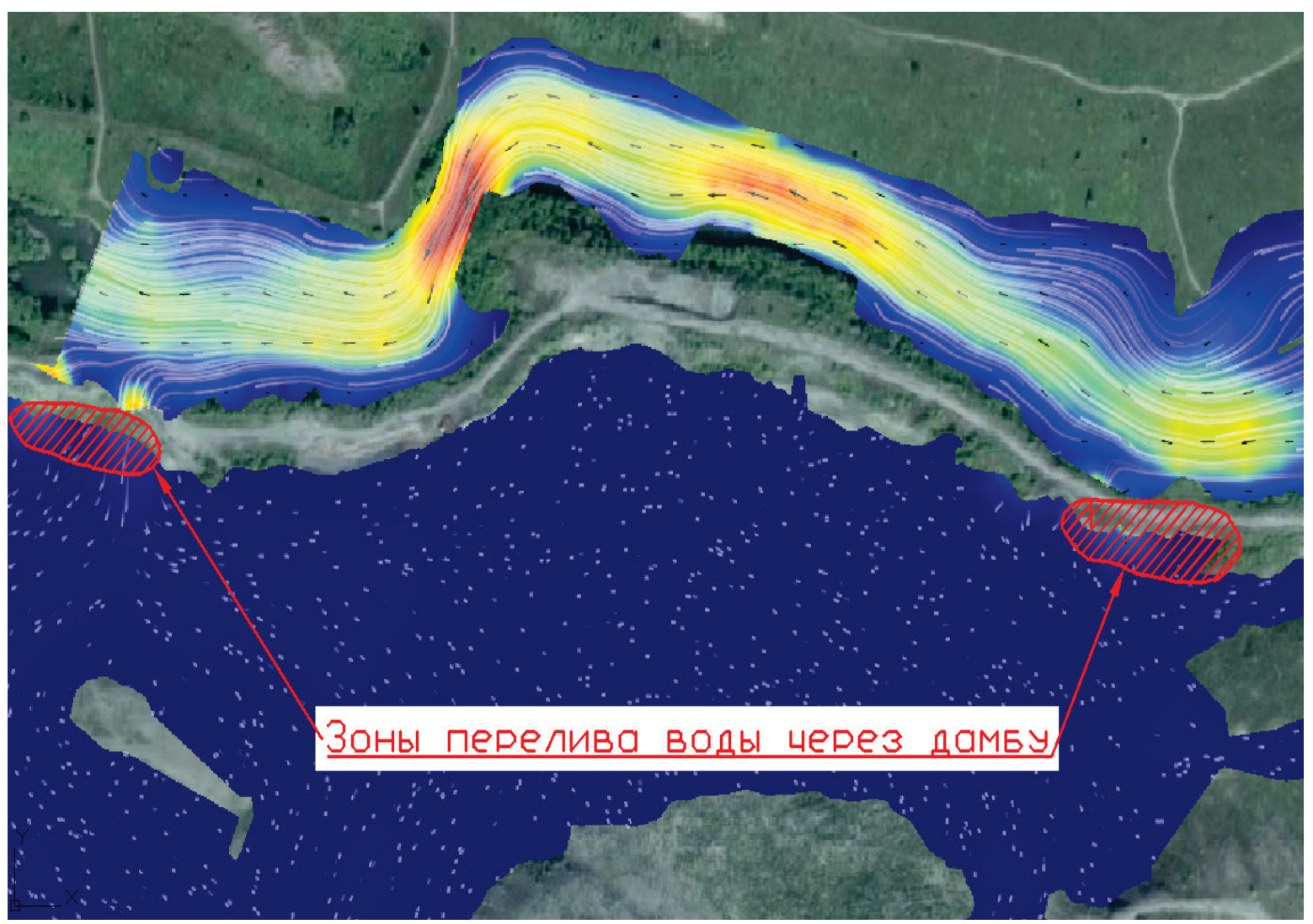

Рис. 10. Локализаиия зон перелива воды через защитную дамбу и распределение направлений течений (белье линии), скоростных векторов (черные стрелки) в плане

Fig. 10. Localization of zones of water overflow through a protective dam and distribution of directions of flows (white lines), velocity vectors (black arrows) in plan

0,10-0,20 м от отметки ее гребня. Однако этого может быть достаточно, чтобы за переливом последовал размыв и прорыв земляной дамбы. По двум выявленным участкам рекомендованы мероприятия по укреплению откосов и подсыпке дамбы на всем протяжении.

В заключение стоит отметить, что моделирующая система HEC-RAS поколения 5 показала себя в довольно выгодном свете по сравнению с версиями предыдущего поколения 4. Особенно заметны улучшения в плане реализации алгоритмов расчета и интерфейсов в работе с $2 \mathrm{D}$ моделями. С недавнего времени в функционал версии 5.0.5 добавлены инструменты моделирования и учета различных гидротехнических сооружений (дамб, водопропускных сооружений и др.) в $2 \mathrm{D}$ режиме, что в большинстве случаев позволяет вообще отказаться от использования 1D моделирования. Работа в режиме 2D моделирования позволяет, имея ЦМР, вносить в нее корректировки (добавлять результаты русловых съемок в ЦМР, снятую без рельефа русла реки), встраивать напрямую в поверхность новые объекты (проектируемые дамбы, отвалы, промплощадки или горные выработки), добавлять в модель гидротехнические сооружения, учитывать коэффициенты шероховатости в виде областей (полигонов). В качестве дополнительных ин- струментов, облегчающих работу и представление результатов, стоит отметить возможность добавления различных растровых и векторных слоев, спутниковых снимков и карт, многие из которых доступны в онлайн библиотеке, а также возможность быстрого вычерчивания продольных и поперечных профилей с нанесением расчетного уровня воды по заданным пользователем направлениям и т. д. Из функциональных недостатков можно отметить отсутствие истинной 3D визуализации, сильную чувствительность к некорректно заданной величине расчетной ячейки и временного шага при отсутствии обратной связи с пользователем (программа не даст знать, что значения подобраны неверно), что может давать значительные погрешности, в связи с чем необходима обязательная калибровка модели по эмпирически полученным параметрам, а также определенный опыт работы с данным ПО.

\section{Выводы}

1. Автором отмечено, что при решении задачи моделирования расчетных зон затопления рек в мировой и отечественной инженерной и научной практике наиболее распространенными подходами являются геометрический и гидравлический. 
2. Оба рассмотренных подхода эффективно решают задачу моделирования зон затопления, но имеют определенные ограничения по использованию.

3. Геометрический подход может быть использован при решении рассматриваемой задачи, однако дает удовлетворительные результаты лишь в узком спектре задач и имеет существенные ограничения по применению, не учитывает реальных физических процессов при движении потока (коэффициенты шероховатости, вязкость жидкости, силы инерции и т. д.), однако менее прихотлив в отношении исходных данных и вычислительных мощностей.

4. Гидравлический подход может быть использован при решении более широкого спектра задач моделирования, он наиболее точно описывает

\section{СПИСОК ЛИТЕРАТУРЫ}

1. Виноградов Ю.Б., Виноградова Т.А. Математическое моделирование в гидрологии. - М.: ИЦ «Академия», 2010. - 304 с.

2. Dingman L. Physical hydrology. Third edition. - Long Grove, Illinois: Waveland press, Inc., 2015. - $643 \mathrm{c}$.

3. СП 47.13330.2016. Инженерные изыскания для строительства. Основные положения. Актуализированная редакция СНиП 11-02-96. - М.: Минстрой России, 2016. - 160 с.

4. СП 33-101-2003. Определение основных расчетных гидрологических характеристик. - М.: Госстрой РФ, 2003. - 73 с.

5. US Army Corps of Engineers. HEC-RAS River analysis system // Hydraulic reference manual. Version 5.0. - 2016. - $547 \mathrm{p}$.

6. US Army Corps of Engineers. HEC-RAS River analysis system // 2D Modeling user's manual. Version 5.0. - 2016. - 171 p.

7. Сиразетдинова Д.Д., Клеин А.Н., Абдуллин А.Х. Моделирование затопления территорий с использованием Arcgis PR0 // Информационные технологии. Проблемы и решения. - 2017. № 1 (4). - C. 195-199.

8. Чечин А.В., Анисимова Э.С. Моделирование зон затопления с использованием геоинформационных систем для оценки ущерба объектам недвижимости // Великие реки 2015: Труды конгресса 17-го Международного научно-промышленного форума. в 3-х т. - Нижний Новгород, 2015. - С. 467-468.

9. Голубева А.Б. Зоны затопления для равнинных рек Алтайского края, расчет ущербов и анализ рисков // Известия А0 РГО. - 2015. - № 4 (39). - С. 43-48.

10. Шихов А.Н., Абдуллин Р.К. Моделирование зон затопления при образовании ледового покрова на реках с помощью ГИСтехнологий (на примере с. Бобровка и пос. Усьва Пермского края) // Геоинформационное обеспечение пространственного развития Пермского края. Сборник научных трудов. - Пермь: Пермский государственный национальный исследовательский университет, 2013. - С. 41-55.

11. Методика составления цифровых карт глубин затопления дорожно-транспортных сетей паводковыми водными потоками / Д.В. Филиппов, И.Н. Чурсин, В.Н. Орлянкин, И.А. Бубер // Заметки ученого. - 2016. - № 9 (15). - С. 78-84.

12. EarthExplorer. URL: https://earthexplorer.usgs.gov/ (дата обращения 28.01.2019).

13. Олудина 0.В., Шигапов И.С. Определение опасных для застройки зон в долине р. Киндерка (г. Казань) // Международный научно-исследовательский журнал. - 2017. - № 10-3 (64). C. 51-56. D0I: https://doi.org/10.23670/IRJ.2017.64.045.

14. Hartnett M., Nash S. High-resolution flood modeling of urban areas using MSN Flood // Water Science and Engineering. 2017. - № 10 (3). - P. 175-183. физическую суть гидродинамических процессов, учитывает различные режимы движения жидкости, однако достаточно требователен в отношении количества и качества исходных данных, а также вычислительных мощностей ЭВМ, более дорогой.

5. Применение численных методов моделирования расчетных зон затопления рек с использованием современных ГИС технологий и моделирующих систем, в том числе свободно распространяемых, таких как HEC-RAS, позволяет более детально изучать происходящие при наводнениях процессы, выявлять опасные с этой точки зрения зоны, а также давать более обоснованные рекомендации по инженерной защите проектируемых объектов или проведению дополнительных, более детальных изысканий.

15. Yongzhi L., Wenting Z., Xinmin C. Flood emergency management using hydrodynamic modelling // Procedia Engineering. 2012. - V. 28. - P. 750-753. URL: https://doi.org/10.1016/ j.proeng.2012.01.802 (дата обращения 28.01.2019).

16. Use of GIS-environment under the Analysis of the Managerial Solutions for Flood Events Protection Measures / A. Nikonorov, V. Badenko, V. Terleev, I. Togo, Yu. Volkova, O. Skvortsova, 0. Nikonova, S. Pavlov, W. Mirschel // Procedia Engineering. 2016. - V. 165. - P. 1731-1740. URL: https://doi.org/10.1016/ j.proeng.2016.11.916 (дата обращения 28.01.2019).

17. Application of 2D numerical simulation for the analysis of the February 2014 Bolivian Amazonia flood: Application of the new HEC-RAS version 5 / V. Moya Quiroga, S. Kure, K. Udo, A. Mano // RIBAGUA - Revista Iberoamericana del Agua. - 2016. V. 3. - Iss. 1. - P. 25-33. URL: https://doi.org/10.1016/j.riba.2015.12.001 (дата обращения 28.01.2019).

18. Первая компьютерная модель течений в межгорной котловине при сбросе ледниково-подпрудного озера (на примере Курайской котловины, Горный Алтай) / Н.Г. Инишев, А.Н. Рудой, В.А. Земцов, Д.А. Вершинин // Доклады Академии Наук. 2015. - T. 461. - № 2. - C. 220-222.

19. Improving the TanDEM-X Digital Elevation Model for flood modelling using flood extents from Synthetic Aperture Radar images / D. Mason, M. Trigg, J. Garcia-Pintado, H. Cloke, J. Neal, P. Bates // Remote Sensing of Environment. - 2016. - V. 173. P. 15-28. URL: https://doi.org/10.1016/j.rse.2015.11.018 (дата обращения 28.01.2019).

20. Коротин А.С., Попов Е.В. Оценка точности цифровых моделей рельефа, применяемых для территориальных исследований // Графикон 2015. Труды Юбилейной 25-й Международной научной конференции. - Нижний Новогород, 2015. - С. 102-106.

21. Alonso R., Santillana M., Dawson C. On the diffusive wave approximation of the shallow water equations // Journal of applied mathematics. - 2008. - V. 19. - P. 575-606. URL: https://doi.org/ 10.1017/S0956792508007675 (дата обращения 28.01.2019).

22. Feng K., Molz F. A 2-D, diffusion-based, wetland flow model // Journal of Hydrology. - 1997. - V. 196. - Iss. 1-4. - P. 230-250. URL: https://doi.org/10.1016/S0022-1694(96)03282-9 (дата обращения 28.01.2019).

23. Candy A. An implicit wetting and drying approach for non-hydrostatic baroclinic flows in high aspect ratio domains // Advances in Water Resources. - 2017. - V. 102. - P. 188-205. URL: https://doi.org/10.1016/j.advwatres.2017.02.004 (дата обращения 28.01.2019).

24. Casulli V. Semi-implicit finite difference methods for the two-dimensional shallow water equations // Journal of Computational 
Physics. - 1990. - V. 86. - Iss. 1. - P. 56-74. URL: https://doi.org/10.1016/0021-9991(90)90091-E (дата обращения 28.01.2019).

25. Balzano A. Evaluation of methods for numerical simulation of wetting and drying in shallow water flow models // Coastal Engineering. - 1998. - V. 34. - Iss. 1-2. - P. 83-107. URL: https://doi.org/10.1016/S0378-3839(98)00015-5 (дата обращения 28.01.2019).

26. Casulli V. Semi-implicit subgrid modelling of three dimensional free-surface flows / International journal for numerical methods in fluids. - 2011. - V. 67. - Iss. 4. - P. 441-449. URL: https:// doi.org/10.1002/fld.2361 (дата обращения 28.01.2019).

27. Arcement G., Schneider V. Guide for selecting Manning's roughness coefficients for natural channels and flood plains. U.S. Geo- logical survey water-supply paper 2339. - U.S.: Government printing office, 1989. $-38 \mathrm{p}$.

28. Панина Н.А. Ресурсы поверхностных вод СССР. - Л.: Гидрометеоиздат, 1972. - 98 с.

29. Ежегодные данные о режиме и ресурсах поверхностных вод суши 1966 г. - Новосибирск: МСС Госгидромета, 1968. - Т. 6. Вып. 0-3. -535 c.

30. Сазонов А.А., Крыленко И.Н., Головлев П.П. Оценка эффективности противопаводковых дамб́ с помощью методов математического моделирования (на примере реки Томь у города Междуреченска) // Природообустройство. - 2015. - № 4. C. $73-76$.

Поступила 04.02.2019 2.

\section{Информация об авторах}

Романовский P.B., руководитель группы инженерно-гидрометеорологических изысканий ОАО «Кузбассгипрошахт». 


\title{
APPLICATION OF COMPUTER MODELING METHODS OF FLOOD ZONES AT MAXIMUM DESIGN WATER LEVELS FOR SOLVING PROJECT TASKS IN THE DISTURBED LANDS RECULTIVATION AND DESIGN OF BUILDINGS AND FACILITIES NEAR WATER BODIES
}

\author{
Roman V. Romanovskiy, \\ keny146@gmail.com \\ Hydrometeorological Survey Group for JSC Kuzbassgiproshakht, \\ 34, N. Ostrovskiy street, Kemerovo, 650000, Russia.
}

\begin{abstract}
The relevance of modeling zones of maximum flooding of rivers (flood zones) during engineering surveys for design and construction of economic activity objects, development of projects for the disturbed lands recultivation in the zones of direct impact of water bodies is related to the fact that under current conditions, with ever-increasing requirements for security and business continuity of the projected facilities, the existing methods for assessing the risk of flooding do not always give a satisfactory result in order to fully assess whether there is a risk for the projected facility or not.

The main aim of the research is to analyze domestic and foreign experience in modeling flood zones at maximum river water levels for practical solution of problems of engineering design, to assess advantages and disadvantages of the main approaches in the practice of surveys, to demonstrate the possibilities of modeling method for solving a particular engineering problem.

Methods. The method of spatial data analysis for creating a digital terrain model via geoinformation systems was used for preparing initial data; the method of numerical simulation of the Inya river flood zone and the abandoned quarry excavation located on the left bank as part of the works on preparation of the project for the disturbed lands recultivation was used to calculate the maximum flood zone. Numerical modeling was carried out using HEC-RAS simulation system, ver. 5.0.5.

Results. The author has carried out the review of the existing worldwide and domestic practice of numerical modeling of flood zones for rivers when solving the problems in the field of engineering design. The paper introduces the author's own model of the calculated flood zone on the example of the recultivation site "Mokhovskoye pole». The example of assessment of the impact on the recultivated object when implementing the most negative scenario (probable flooding of the pit in the period of the maximum water flow of $1 \%$ occurrence) was shown, the advantages and disadvantages of applying different approaches in practice were described.
\end{abstract}

\section{Key words:}

Geoinformation systems, numerical modeling of the flood zones of rivers, 2D modeling,

digital elevation model, remote sensing data, modeling systems, HEC-RAS.

\section{REFERENCES}

1. Vinogradov Yu.B., Vinogradova T.A. Matematicheskoe modelirovanie $v$ gidrologii: [Mathematical modeling in hydrology]. Moscow, Akademiya Publ., 2010. 304 p.

2. Dingman L. Physical hydrology. Long Grove, Illinois, Waveland press, Inc., 2015. 643 p.

3. SP 47.13330.2016. Inzhenernyye izyskaniya dlya stroitelstva. Osnounyye polozheniya. Aktualizirovannaya redaktsiya SNiP 11-02-96 [Engineering surveys for construction. Basic provisions. Updated version of SNiP 11-02-96]. Moscow, Ministry of Construction of the RF Publ., 2016.

4. SP 33-101-2003. Opredelenie osnounykh raschetnykh gidrologicheskikh kharakteristik [Determination of design hydrological performance]. Moscow, Gosstroy RF Publ., 2003. 73 p.

5. US Army Corps of Engineers. HEC-RAS River analysis system. Hydraulic reference manual. Version 5.0., 2016. 547 p.

6. US Army Corps of Engineers. HEC-RAS River analysis system. $2 D$ Modeling user's manual. Version 5.0., 2016. 171 p.

7. Sirazetdinova D.D., Klein A.N., Abdullin A.Kh. Modeling of flooding of territories using Arcgis PRO. Informatsionnye tekhnologii. Problemy i resheniya, 2017, no. 1 (4), pp. 195-199. In Rus.

8. Chechin A.V., Anisimova E.S. Modelirovanie zon zatopleniya s ispolzovaniem geoinformatsionnykh sistem dlya otsenki ushcherba obektam nedvizhimosti [Modeling flood zones using geoinformation systems to assess damage to real estate objects]. Trudy kongressa 17-go Mezhdunarodnogo nauchno-promyshlennogo foruma. Velikie reki 2015 [Proc. of the Congress of the $17^{\text {th }}$ International Scientific and Industrial Forum. Great Rivers 2015]. Nizhniy Novgorod, 2015. pp. 467-468.

9. Golubeva A.B. Zones of flooding for the flat rivers of the Altai Territory, calculation of damages and risk analysis. Izvestiya AO RGO, 2015, no. 4 (39), pp. 43-48. In Rus.
10. Shikhov A.N., Abdullin R.K. Modelirovanie zon zatopleniya pri obrazovanii ledovogo pokrova na rekakh s pomoshchyu GIStekhnologiy (na primere s. Bobrovka i pos. Usva Permskogo kraya) [Modeling of flooding zones in ice cover formation on rivers with the help of GIS-technologies (on the example of Bobrovka and Usva settlements, Perm Krai)] Geoinformatsionnoe obespechenie prostranstvennogo razvitiya Permskogo kraya. Sbornik nauchnykh trudov [Geoinformation support for spatial development of Perm Krai. Collection of scientific papers]. Perm, Perm State National Research University Publ., 2013. pp. 41-55.

11. Filippov D.V., Chursin I.N., Orlyankin V.N., Buber I.A. Methodology of compilation of digital maps of flood depths of road and transport networks by flooding water flows. Zametki uchenogo, 2016, no. 9 (15), pp. 78-84. In Rus.

12. EarthExplorer. Available at: https://www.earthexplorer.usgs. gov/ (accessed 28 January 2019).

13. Oludina 0.V., Shigapov I.S. Identification of hazardous areas for development in the valley of the Kinderka river (Kazan). Mezhdunarodny nauchno-issledovatelskiy zhurnal, 2017, no. 10-3 (64), pp. 51-56. In Rus. DOI: https://doi.org/10.23670/IRJ.2017.64.045.

14. Hartnett M., Nash S. High-resolution flood modeling of urban areas using MSN_Flood. Water Science and Engineering, 2017, no. $10(3)$, pp. $1 \overline{7} 5-183$.

15. Liu Y., Zhang W., Cui X. Flood emergency management using hydrodynamic modelling. Procedia Engineering, 2012, vol. 28, pp. 750-753. Available at: https://doi.org/10.1016/j.proeng.2012.01.802 (accessed 28 January 2019).

16. Nikonorov A., Badenko V., Terleev V., Togo I., Volkova Y., Skvortsova 0., Nikonova 0., Pavlov S., Mirschel W. Use of GISenvironment under the Analysis of the Managerial Solutions for Flood Events Protection Measures. Procedia Engineering, 2016, 
vol. 165, pp. 1731-1740. Available at: https://doi.org/ 10.1016/j.proeng.2016.11.916 (accessed 28 January 2019).

17. Moya Quiroga V., Kure S., Udo K., Mano A. Application of 2D numerical simulation for the analysis of the February 2014 Bolivian Amazonia flood: Application of the new HEC-RAS version 5. RIBAGUA - Revista Iberoamericana del Agua, 2016, vol. 3, Iss. 1, pp. 25-33. Available at: https://doi.org/10.1016/j.riba.2015.12.001 (accessed 28 January 2019).

18. Inishev N.G., Rudoi A.N., Zemtsov V.A., Vershinin D.A. The first computer model of currents in the intermontane basin when discharging the glacial-pond lake (on the example of Kuraisk depression, Gorny Altai). Doklady Akademii Nauk, 2015, vol. 461, no. 2 , pp. 220-222.

19. Mason D., Trigg M., Garcia-Pintado J., Cloke H., Neal J., Bates P. Improving the TanDEM-X Digital Elevation Model for flood modelling using flood extents from Synthetic Aperture Radar images. Remote Sensing of Environment, 2016, vol. 173, pp. 15-28. Available at: https://doi.org/10.1016/j.rse. 2015.11.018 (accessed 28 January 2019).

20. Korotin A.S., Popov E.V. Otsenka tochnosti tsifrovykh modeley relefa, primenyaemykh dlya territorialnykh issledovaniy [Evaluation of the accuracy of digital elevation models used for territorial research]. Grafikon 2015. Trudy Yubileynoy 25-y Mezhdunarodnoy nauchnoy konferentsii [Graphicon 2015. Proc. of the Jubilee $25^{\text {th }}$ International Scientific Conference]. Nizhniy Novgorod, 2015. pp. 102-106.

21. Alonso R., Santillana M., Dawson C. On the diffusive wave approximation of the shallow water equations. Journal of applied mathematics, 2008, vol. 19, pp. 575-606. Available at: https://doi.org/10.1017/S0956792508007675 (accessed $28 \mathrm{Ja}$ nuary 2019).

22. Feng K., Molz F. A 2-D, diffusion-based, wetland flow model. Journal of Hydrology, 1997, vol. 196, Iss. 1-4, pp. 230-250. Available at: https://doi.org/10.1016/S0022-1694(96)03282-9 (accessed 28 January 2019).
23. Candy A. An implicit wetting and drying approach for non-hydrostatic baroclinic flows in high aspect ratio domains. Advances in Water Resources, 2017, vol. 102, pp. 188-205. Available at: https://doi.org/10.1016/j.advwatres.2017.02.004 (accessed 28 January 2019).

24. Casulli V. Semi-implicit finite difference methods for the two-dimensional shallow water equations. Journal of Computational Physics, 1990, vol. 86, Iss. 1, pp. 56-74. Available at: https://doi.org/10.1016/0021-9991(90)90091-E (accessed 28 January 2019).

25. Balzano A. Evaluation of methods for numerical simulation of wetting and drying in shallow water flow models. Coastal Engineering, 1998, vol. 34, Iss. 1-2, pp. 83-107. Available at: https://doi.org/10.1016/S0378-3839(98)00015-5 (accessed 28 January 2019).

26. Casulli V. Semi-implicit subgrid modelling of three dimensional free-surface flows. International journal for numerical methods in fluids, 2011, vol. 67, Iss. 4, pp. 441-449. Available at: https://doi.org/10.1002/fld.2361 (accessed 28 January 2019).

27. Arcement G., Schneider V. Guide for selecting Manning's roughness coefficients for natural channels and flood plains. U.S.Geological survey water-supply paper 2339. U.S. Government printing office, 1989. $38 \mathrm{p}$.

28. Panina N.A. Resursy poverkhnostnykh vod SSSR [Resources of the USSR surface waters]. Leningrad, Gidrometeoizdat Publ., $1972.98 \mathrm{p}$

29. Ezhegodnye dannye o rezhime i resursakh poverkhnostnykh vod sushi $1966 \mathrm{~g}$. [Annual data on the regime and resources of surface waters of the land, year 1966]. Novosibirsk, MSS Gosgidromet, 1968. Vol. 6, Iss. 0-3, $535 \mathrm{p}$

30. Sazonov A.A., Krylenko I.N., Golovlev P.P. Assessment of the effectiveness of flood control dams using mathematical modeling methods (on the example of the Tom river in the city of Mezhdurechensk). Prirodoobustroystvo, 2015, no. 4, pp. 73-76. In Rus.

Received: 4 February 2019.

\section{Information about the authors}

Roman V. Romanovskiy, Head of Engineering Hydrometeorological Survey Group for JSC Kuzbassgiproshakht. 